\title{
Acute Effect of Sodium Bicarbonate Supplementation on Symptoms of Gastrointestinal Discomfort, Acid-Base Balance, and Performance of Jiu-Jitsu Athletes
}

\author{
by \\ Luciano Ragone', João Guilherme Vieira², Mateus Camaroti Laterza², Luis Leitão3, \\ Jefferson da Silva Novaes ${ }^{4}$, Jeferson Macedo Vianna², Marcelo Ricardo Dias ${ }^{1}$
}

The purpose of the present study was to verify the acute effect of sodium bicarbonate supplementation on symptoms of gastrointestinal discomfort, acid-base balance and intermittent isometric handgrip test performance in JiuJitsu athletes. Ten male (22.2 \pm 3.9 years; $174 \pm 0.07 \mathrm{~cm} ; 74.5 \pm 8.9 \mathrm{~kg})$ jiu-jitsu athletes participated in this counterbalanced double-blind crossover study. Two protocols, a) supplementation with $0.3 \mathrm{~g} \cdot \mathrm{kg}^{-1}$ of body weight of sodium bicarbonate, and b) supplementation with $0.045 \mathrm{~g}^{\mathrm{kg}-1}$ of body weight of placebo substance, were employed. Gastrointestinal tolerability was assessed by the questionnaire. Blood samples were collected at three time points (baseline, pre-ISO, and post-ISO) to determine the responses of potential hydrogenionic $(\mathrm{pH})$, bicarbonate $\left(\mathrm{HCO}_{3}{ }^{-}\right.$), base excess $(E B)$ and lactate concentrations. The maximum voluntary contraction test and the intermittent isometric contraction test were also performed. As a result, none of the athletes reported significant gastrointestinal discomfort ( $p$ $>0.05)$. $\mathrm{HCO}_{3}, \mathrm{pH}$, and $\mathrm{EB}$ at the pre-ISO and post-ISO moments were significantly higher for the sodium bicarbonate protocol. Lactate concentrations were significantly higher for both post-ISO protocols $(p=0.000)$. There was no significant difference in the performance of the maximum voluntary contraction test and the intermittent isometric contraction test $(p>0.05)$. Thus, we conclude that sodium bicarbonate supplementation does not generate adverse responses resulting in gastrointestinal discomfort, and does not benefit performance yet promotes a state of metabolic alkalosis.

Key words: $\mathrm{NaHCO}_{3}$, metabolic alkalosis, martial arts, handgrip exercise, intermittent exercise.

\section{Introduction}

Sodium

bicarbonate

$\left(\mathrm{NaHCO}_{3}\right)$

supplementation has been employed to improve performance in high-intensity activities, where the primary energy source is predominantly from the anaerobic glycolytic pathway (Artioli et al., 2007; Chycki et al., 2018b; Durkalec-Michalski et al., 2018; Lopes-Silva et al., 2018), due to the greater need to buffer the hydrogen ions $\left(\mathrm{H}^{+}\right)$released by the dissociation of lactic acid molecules formed in large quantities in the sarcoplasm during high

\begin{abstract}
intensity exercise, causing the reduction of intramuscular $\mathrm{pH}$ and having a direct relation with the development of fatigue (Chin and Allen, 1998; Fabiato and Fabiato, 1978; Spriet et al., 1989; Westerblad and Allen, 1993). Thus, supplementation with $\mathrm{NaHCO}_{3}$ increases the extracellular reserve of bicarbonate $\left(\mathrm{HCO}_{3}{ }^{-}\right)$and increases blood $\mathrm{pH}$, which enables more effective removal of $\mathrm{H}^{+}$ions accumulated in intracellular fluid by forming a positive electrochemical
\end{abstract}

\footnotetext{
1 - Laboratory of Exercise Physiology and Morphofunctional Assessment, Granbery Methodist College, Juiz de Fora, Brazil.

2 - Faculty of Physical Education Sports, Federal University of Juiz de Fora, Brazil.

3 - Superior School of Education of Polytechnic Institute of Setubal, Setúbal, Portugal.

4 - Gymnastics Department, Federal University of Rio de Janeiro, Brazil.
} 
gradient to displace these ions out of active muscle fibers, which would result in delayed muscle fatigue (Chycki et al., 2018a; Siegler and Hirscher, 2010; Van Montfoort et al., 2004; Verbitsky et al., 1997).

The positive effects of an environment more conducive to the regulation of muscular $\mathrm{pH}$ for sports performance have been extensively investigated, however, most of the studies have been limited mainly to examining its effects on activities that basically involve dynamic muscle actions (Artioli et al., 2007; Driller et al., 2013; Durkalec-Michalski et al., 2018; Lopes-Silva et al., 2018).

In some sports, such as Jiu-Jitsu, athletes perform successive isometric handgrip actions for specific techniques that require an enhanced ability to produce isometric force (Oliveira et al., 2006). Thus, depending on the intensity of contraction, an isometric effort may cause a partial or a complete decrease of the blood flow in the active musculature due to the mechanical compression exerted on the vessels, thus a greater contribution of the anaerobic system becomes necessary to maintain the energy demand of this activity (Hunter et al., 2009). According to Franchini et al. (2011), it has been considered that the main adaptation to training of athletes would be the increase in muscular endurance since during the fight repetitive vigorous isometric actions with short recovery intervals between them are necessary.

The measurement of isometric resistance may be more relevant for the evaluation of athletes than the maximum strength measurement. Therefore, in association with more a pronounced blood flow observed at intervals between isometric contractions as an adaptation to training, it is expected that Jiu-Jitsu athletes can benefit from $\mathrm{NaHCO}_{3}$ supplementation, as this substance may contribute to the delay of fatigue (Junior et al., 2015). However, we should pay attention to gastrointestinal discomfort, since it may affect performance and impair the ergogenic effects of $\mathrm{NaHCO}_{3}$ supplementation (Cameron et al., 2010). Therefore, the purpose of the present study was to verify the acute effects of sodium bicarbonate supplementation on symptoms of gastrointestinal discomfort, acid-base balance and intermittent isometric handgrip test performance in Jiu-Jitsu athletes.

\section{Methods}

\section{Participants}

Ten men jiu-jitsu athletes $(22.2 \pm 3.9$ years; $174 \pm 0.07 \mathrm{~cm} ; 74.5 \pm 8.9 \mathrm{~kg}$ ) with uninterrupted experience of more than three years in jiu-jitsu competition, blue belt graduates and affiliated to the Brazilian Jiu-Jitsu Confederation, participated in this study. The sample size was determined using $G^{*}$ power software (version 3.1.9.2, Heinrich-Heine-Universitat in Dusseldorf, Germany) (Faul et al., 2007) and was considered to have a power of $0.80, \alpha$ of 0.05 and an effect size of 0.5 , with a statistical power of $89.2 \%$, calculated by the procedures suggested by Beck (2013). In addition, athletes did not experience discomfort or any injury, did not consume food supplements nor medications, and answered negatively to all questions from the Physical Activity Readiness Questionnaire (PAR-Q). After agreeing to participate in the research, athletes signed an informed consent form, and all procedures were conducted in accordance with the ethical standards of the Helsinki Declaration (1964) and approved by the local ethics committee.

\section{Experimental overview}

A counterbalanced double-blind crossover design was used in this study which took place over three visits (Figure 1).

During the first visit, the athletes performed anthropometric measurements and were familiarized with the test protocols. During the second and third visits, athletes were randomly assigned to counterbalance input in two protocols: a) Gastrointestinal Tolerability Assessment (GI) $+0.3 \mathrm{~g} \cdot \mathrm{kg}^{-1} \mathrm{NaHCO}_{3}+\mathrm{GI}+$ Maximum voluntary contraction test (MVC Test) + Intermittent isometric contraction Test (ISO

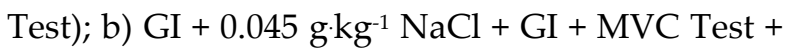
ISO Test. A period of 7 days between protocols was respected and all tests were performed at the same time of day to minimize circadian variation. In both protocols, athletes initially answered the GI questionnaire and immediately after the first blood sample was collected. Ten minutes later they were asked to ingest $\mathrm{NaHCO}_{3}$ or $\mathrm{NaCl}$ every 10 minutes during the next 30 minutes. Then, athletes answered GI three times, separated by time intervals of 20 minutes. Sixty minutes after the total drink intake, the MVC test was started. Following the experiment, after ten minutes of the 
MVC test, the second blood sample was collected and after additional five minutes the ISO test was performed. At the end of the ISO test, the third blood sample was collected. All athletes were instructed not to drink alcohol throughout their study participation, report to the laboratory two hours after their last meal, not to consume caffeine-containing beverages and foods, and not to engage in vigorous exercise or activities that require strong handgrips 24 hours prior to testing.

\section{Supplementation protocol}

Athletes were submitted to two protocols that involved supplementation with an experimental substance $\left(0.3 \mathrm{~g} \mathrm{~kg}^{-1} \mathrm{NaHCO}_{3}^{-}\right)$and another control substance $\left(0.045 \mathrm{~g} \cdot \mathrm{kg}^{-1} \mathrm{NaCl}\right)$, in a counterbalanced double-blind crossover design, before performing the exercises. The dose of 0.3 $\mathrm{g} \mathrm{kg}^{-1} \mathrm{NaHCO}_{3}{ }^{-}$administered in the experimental protocol has been shown to be efficient in inducing a high degree of metabolic alkalosis, in addition to providing greater performance benefits in relation to lower and higher doses of $\mathrm{NaHCO}_{3}{ }^{-}$(McNaughton, 1992). In the control protocol, the $\mathrm{NaCl}$ dose administered was used as a placebo substance, according to previous studies (Cameron et al., 2010; Siegler et al., 2010). A oneweek washout period was adopted to eliminate any residual effect of $\mathrm{NaHCO}_{3}$ - supplementation (Bishop and Claudius, 2005). Both $\mathrm{NaHCO}_{3}$ and $\mathrm{NaCl}$ supplements were dissolved in $600 \mathrm{ml}$ of a low-calorie isotonic beverage with lemon flavor so that any characteristic flavor of $\mathrm{NaHCO}_{3}{ }^{-}$and $\mathrm{NaCl}$ could be eliminated, and were divided into three doses of $200 \mathrm{ml}$; an interval of 10 minutes elapsed between ingestion of each dose. Thus, after ingesting the three doses of $200 \mathrm{ml}, 30$ minutes had passed.

\section{Gastrointestinal Tolerability Assessment (GI)}

Athletes answered the GI questionnaire at two moments: a) before the supplementation; and b) after the supplementation during 20-min intervals. The questionnaire had been validated to measure gastrointestinal discomfort (Jeukendrup et al., 2000) and consisted of six items (nausea, stomach cramps, flatulence, belching, bloating, and diarrhea) grouped together describing common gastrointestinal symptoms. The numerical classification scale (NRS) (scale 0-10, with zero reflecting no gastrointestinal discomfort and 10 indicating the most severe gastrointestinal discomfort) was used to classify the intensity of these symptoms (Dworkin et al., 2005).

Maximum voluntary contraction test (MVC)

The MVC test was performed after the supplementation by measuring the handgrip force with a digital dynamometer with a resolution of $0.1 \mathrm{kgf}(1 \mathrm{~N})$ and a maximum capacity of $100 \mathrm{kgf}$ $(1000 N)$ (Cefise ${ }^{\circledR}$, São Paulo, Brazil). The device offers six handle adjustments ranging from 46 to $98 \mathrm{~mm}$, which allows individual adjustment of the handle to the size of the hand. The N2000 PRO software (Cefise ${ }^{\circledR}$, São Paulo, Brazil) was used to analyze the force.

To perform the tests, athletes were instructed to remain seated on an adjustable bench, so that the hips and knees remained at $90^{\circ}$, with their feet supported on the floor. Regarding the positioning of the upper limb, the shoulder on the dominant side remained in the position near the trunk and the elbow at $90^{\circ}$ with the forearm in a neutral position. The athlete had to maintain the described position holding in his hand the dynamometer that was supported on a stable base, according to a previous study (Oliveira et al., 2006).

Sixty minutes after the supplementation with bicarbonate or a placebo athletes performed the MVC test which consisted of three attempts of five seconds of MVC, separated by two minute rest intervals. During the attempts, there was verbal encouragement and visual feedback of the force produced from a monitor found in front of the athletes at the time of performing the test. The highest value found between the attempts was used as a basis for determining strength. Excellent reliability between the attempts was verified, showing an intraclass correlation coefficient of: $1^{\text {st }}$ attempt, $\mathrm{r}=0.96 ; 2^{\text {nd }}$ attempt, $\mathrm{r}=0.99$; and $3^{\text {rd }}$ attempt, $r=0.97$. In addition, a paired t-test showed no significant difference between the attempts $(p>0.05)$.

\section{Intermittent isometric contraction Test (ISO)}

The ISO test was performed after the MVC test, in the largest number of successive cycles of $5 \mathrm{~s}$ of isometric contraction at $50 \%$ of MVC, followed by $5 \mathrm{~s}$ of relaxation until fatigue. To start the contraction phase of each cycle athletes exerted a force of $50 \%$ of their MVC. The test was interrupted when athletes were unable to generate a minimum strength of $50 \%$ of the MVC in three consecutive cycles of contraction and relaxation. To standardize the test the following 
procedures were adopted: a) there was verbal encouragement and control of the intensity of the test through visual feedback, b) the beginning of the contraction phase was controlled by software through a sound signal emitted by a speaker, and c) the beginning of the relaxation phase was controlled through a verbal stimulus with the word: "relax".

Blood samples

Blood samples were collected at three moments: a) before ingestion of biocarbonate and a placebo; b) after the MVC test; and c) after the ISO test. For each collection, $4 \mathrm{ml}$ of venous blood was drawn from the antecubital vein of the dominant arm with a 20-caliber needle connected to a vacutainer tube (Vacuplast, São Paulo, Brazil) containing heparin. A gasometer (AGS 22 Drake, USA) was used to analyze $\mathrm{pH}, \mathrm{HCO}_{3}-$ and $\mathrm{EB}$ concentrations. Blood lactate was measured using an electromagnetic analyzer (YSL 2300 STAT, Yellow Spring, USA).

\section{Statistical Analysis}

In order to calculate inferential statistics for the data, the normality of the distribution was assessed with the Shapiro-Wilk test and the homoscedasticity with the Levene test. For each attempt of MVC, the reliability of the test was performed, in which the intraclass correlation (ICC) and a paired t-test were used to verify the difference between the attempts. Blood variables were compared for both protocols using a twoway analysis of variance of two factors (ANOVA) with repeated measures 2 (supplementation) $\times 3$ (time points), followed by post hoc analysis with Tukey's correction for multiple comparisons at each time point. For this, the sphericity of the variables was assumed through the Mauchly's test. A paired t-test was used to compare exercise performance (MVC test and ISO test) between protocols. Symptoms of gastrointestinal discomfort were compared between the two protocols in each sampling period, using the Friedman's non-parametric test. The level of significance was set at $p<0.05$. All analyses were performed using SPSS software version 20.0.0 for Mac (SPSS Inc., Chicago, IL, USA).

\section{Results}

The progressive dose supplementation regimen was well tolerated for both protocols $(p=$ 0.388) (Table 1).
The comparison of protocols at pre-ISO and post-ISO times for $\mathrm{pH}, \mathrm{HCO}_{3}$ and $\mathrm{EB}$ showed significantly higher values for the $\mathrm{NaHCO}_{3}$ protocol $(p<0.05)$. When comparing baseline values with pre-ISO, $\mathrm{pH}, \mathrm{HCO}_{3}-$ and $\mathrm{EB}$ were significantly higher only in the $\mathrm{NaHCO} 3$ protocol $(p<0.001)$, but when comparing baseline values with the post-ISO test, only the $\mathrm{NaCl}$ protocol showed a significant decrease $(p<0.001)$. Similar results were found when comparing $\mathrm{pH}, \mathrm{HCO}_{3}-$ and EB obtained in the post-MVC with the postISO test $(p<0.001)$. For lactate concentrations when compared to baseline and pre-ISO values with post-ISO, both values significantly decreased $(p<0.001)$ (Table 2).

In the MVC test, the maximum force and the mean force produced by athletes were not significantly different between the $\mathrm{NaHCO}_{3}{ }^{-}$and $\mathrm{NaCl}$ protocols $(p=0.984)$. When comparing the ISO test for the total number of contractions and the total time of the test, there was no significant difference between the $\mathrm{NaHCO}_{3}$, and $\mathrm{NaCl}$ protocols $(p=0.929)$ (Table 3$)$.

\section{Discussion}

The purpose of the present study was to verify the acute effect of sodium bicarbonate supplementation on symptoms of gastrointestinal discomfort, acid-base balance and intermittent isometric handgrip test performance in Jiu-Jitsu athletes. The results of the present study showed that there were no significant differences in the answers of the GI questionnaire. Blood variables showed significant differences when compared to the experimental protocol with the control protocol. However, lactate only increased significantly in the post-ISO when compared to the basal and pre-ISO test $(p<0.05)$. In test performance, there was no significant difference in the total number of contractions and in the time of performance when the experimental protocol was compared with the control protocol.

For the first time, the efficiency of $\mathrm{NaHCO}_{3}$ - supplementation was verified during isometric contractions of finger flexors in jiu-jitsu fighters. The use of $\mathrm{NaHCO}_{3}$ supplementation depending on the dosage has not been advised as there is an increased incidence of adverse effects such as gastrointestinal distress (Junior et al., 2015). Cameron et al. (2010) performed $\mathrm{NaHCO}_{3}{ }^{-}$ supplementation with a single intake, at the same 
dosage as the present study in professional rugby athletes, and reported gastrointestinal discomfort after ingestion experienced by athletes. Thus, it appears that single dosing caused gastrointestinal discomfort and may have impaired performance of the rugby-specific repeated sprint test. In our study, fractional supplementation was performed in three equal dosages and athletes did not report any discomfort (Carr et al., 2011; Driller et al., 2013).

\section{Table 1}

Incidence of gastrointestinal distress symptoms (GI) 20, 40 and 60 minutes after sodium bicarbonate $\left(\mathrm{NaHCO}_{3}{ }^{-}\right)$and placebo $(\mathrm{NaCl})$ supplementation protocols.

\begin{tabular}{ccccccccc}
\hline & & \multicolumn{2}{c}{$\mathrm{NaHCO}^{-}$} & & \multicolumn{2}{c}{$\mathrm{NaCl}$} \\
\hline & Baseline & $20-\mathrm{PS}$ & $40-\mathrm{PS}$ & $60-\mathrm{PS}$ & Baseline & $20-\mathrm{OS}$ & $40-\mathrm{OS}$ & $60-\mathrm{OS}$ \\
\hline Nausea & $0.25 \pm 0.87$ & $0.50 \pm 1.17$ & $0.25 \pm 0.87$ & $0.25 \pm 0.87$ & $0.00 \pm 0.00$ & $0.50 \pm 1.73$ & $0.25 \pm 0.87$ & $0.25 \pm 0.87$ \\
& & & & & & & \\
Stomach cramps & $0.00 \pm 0.00$ & $0.75 \pm 1.86$ & $0.25 \pm 0.87$ & $0.25 \pm 0.87$ & $0.00 \pm 0.00$ & $0.50 \pm 1.73$ & $0.25 \pm 0.87$ & $0.25 \pm 0.87$ \\
Flatulence & $0.50 \pm 1.17$ & $2.00 \pm 2.34$ & $1.00 \pm 1.48$ & $1.25 \pm 2.38$ & $0.50 \pm 1.17$ & $1.75 \pm 2.01$ & $1.00 \pm 1.48$ & $1.25 \pm 2.01$ \\
Belching & $0.50 \pm 1.17$ & $2.50 \pm 2.50$ & $2.75 \pm 1.36$ & $1.00 \pm 1.48$ & $1.25 \pm 0.87$ & $2.25 \pm 2.26$ & $1.00 \pm 1.48$ & $0.25 \pm 0.87$ \\
Bloating & $1.25 \pm 2.54$ & $3.75 \pm 2.90$ & $2.25 \pm 2.26$ & $1.25 \pm 2.01$ & $1.75 \pm 2.38$ & $3.00 \pm 3.13$ & $2.25 \pm 2.26$ & $2.00 \pm 1.95$ \\
Diarrhea & $0.50 \pm .17$ & $1.25 \pm 2.70$ & $0.50 \pm 1.17$ & $0.75 \pm 1.36$ & $0.00 \pm 0.00$ & $1.25 \pm 2.01$ & $0.25 \pm 0.87$ & $1.00 \pm 1.48$ \\
\hline
\end{tabular}

Data expressed as mean \pm standard deviation.

Table 2

Blood variables (hydrogenionic potential $(\mathrm{pH})$, bicarbonate $\left(\mathrm{HCO}_{3}^{-}\right)$, excess base (EB), and lactate) baseline, pre-ISO and post-ISO for the sodium bicarbonate ( $\mathrm{NaHCO}_{3}{ }^{-}$), and placebo $(\mathrm{NaCl})$ protocols.

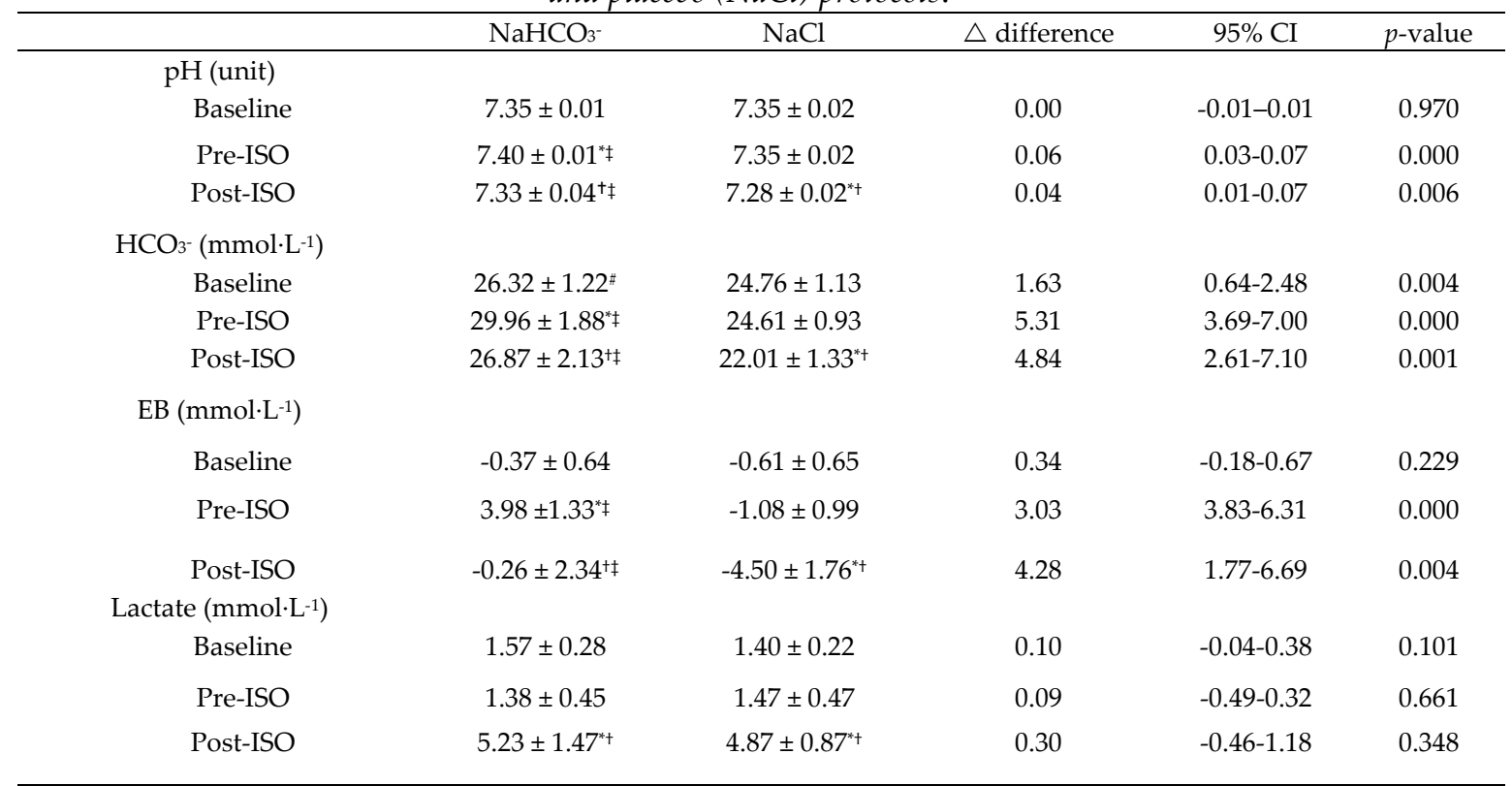

Data expressed as mean \pm standard deviation; * Significant difference from baseline values $(p<0.05)$; + Significant difference from pre-ISO ( $p<0.05)$; $\neq$ Significant difference from the NaCl protocol $(p<0.05)$. 
Table 3

Exercise performance of the maximum voluntary contraction test (MVC) and intermittent isometric contraction test (ISO) for the sodium bicarbonate ( $\left.\mathrm{NaHCO}_{3}{ }^{-}\right)$ and placebo $(\mathrm{NaCl})$ protocols.

\begin{tabular}{lccccc}
\hline & $\mathrm{NaHCO}_{3}{ }^{-}$ & $\mathrm{NaCl}$ & $\triangle$ difference & $95 \% \mathrm{CI}$ & $p$-value \\
\hline MVC Test & & & & & \\
$\quad$ Maximum (Kgf) & $44.40 \pm 12.55$ & $44.40 \pm 11.48$ & 0.13 & $-1.65-1.65$ & 1.000 \\
$\quad$ Average (Kgf) & $40.08 \pm 12.32$ & $40.21 \pm 10.75$ & 0.13 & $-1.89-1.69$ & 0.903 \\
ISO Test & & & & \\
$\quad$ Total contractions (reps) & $56.20 \pm 27.69$ & $55.30 \pm 31.49$ & 0.90 & $-21.54-32.34$ & 0.930 \\
$\quad$ Total time (min) & $9.35 \pm 4.62$ & $9.22 \pm 5.25$ & 0.15 & $-3.60-3.87$ & 0.938 \\
\hline
\end{tabular}

Data expressed as mean \pm standard deviation.

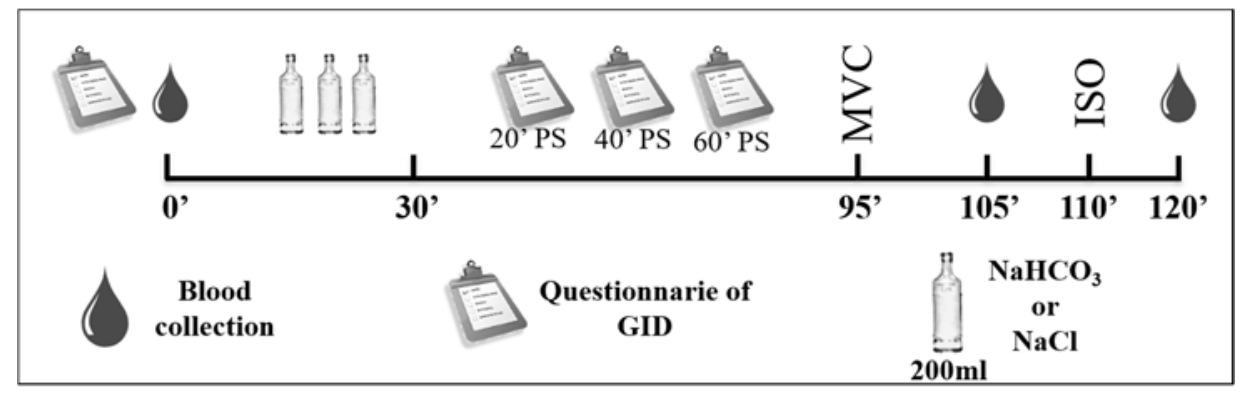

Figure 1

Experimental design of the study

According to Siegler et al. (2010), $\mathrm{NaHCO}_{3}$ - supplementation using a dosage of 0.3 g. $\mathrm{kg}^{-1}$ induces metabolic alkalosis peak between 60 and 90 minutes after supplementation. Thus, it seems that there is a time dependence between the end of the supplementation intake and the beginning of the exercise, since in the present study as in others (Cameron et al., 2010; Kumstát et al., 2018; Siegler et al., 2015; Siegler et al., 2016) there was a time between 60 and $90 \mathrm{~min}$ for blood collection and subsequent start of the test. This explains the increase in $\mathrm{pH}, \mathrm{HCO}_{3}$ - and $\mathrm{EB}$ at the pre-ISO test, indicating a high degree of supplemental-induced metabolic alkalosis (Chycki et al., 2018a). However, at the post-ISO test time, there was a reduction in blood $\mathrm{pH}$ that may be explained by the dissociation of lactic acid molecules formed in large quantities in the 
sarcoplasm during exercise (Chin and Allen, 1998) altering the levels of $\mathrm{HCO}_{3}$-, which become decreased due to the need to buffer the $\mathrm{H}+$ ions released into the bloodstream after exertion and thus reducing the EB value.

For blood lactate, there was no difference between the protocols, and lactate concentration increased significantly at the post-ISO test compared to the baseline and pre-ISO test. Some studies that used dynamic tests involving greater muscle mass observed a significant increase in lactate when $\mathrm{NaHCO}_{3}$ - supplementation was administered (Cameron et al., 2010; Ferreira et al., 2019; Lopes-Silva et al., 2018). Therefore, it seems that in the present study, because it involved isometric exercise performed with a small amount of muscle mass (finger flexor muscles), $\mathrm{NaHCO}_{3}$ supplementation was not able to generate sufficient efflux of $\mathrm{H}+$ ions from muscle cells to extracellular medium, capable of increasing blood lactate levels at post-ISO time.

Although the alkalotic state was induced by $\mathrm{NaHCO}_{3}$ - supplementation in the blood before the isometric handgrip test, our results did not show the efficacy of $\mathrm{NaHCO}_{3}$ - supplementation. Our findings corroborate those of Siegler et al. (2014) who used $\mathrm{NaHCO}_{3}$ - supplementation to perform isometric contractions of the sural triceps. However, the above findings contrast with other studies that have verified the effectiveness of $\mathrm{NaHCO}_{3}$ - supplementation on large muscles in isometric contractions (Hunter et al., 2009; Siegler and Marshall, 2015; Verbitsky et al., 1997) and in dynamic work (Artioli et al., 2007; Chycki et al., 2018b; Durkalec-Michalski et al., 2018; Lopes-Silva et al., 2018). It appears that $\mathrm{NaHCO}_{3}-$ supplementation before exercise in small muscle groups may be less effective for performing isometric contractions when compared to large muscle groups. This may be explained by the fact that intermittent isometric contractions for task fatigue in small muscle clusters are not affected by changes in blood variables, but are affected by central and peripheral aspects (Siegler et al., 2015).
One mechanism that can best elucidate the limited ergogenic effect of $\mathrm{NaHCO}_{3}$ - supplementation on exercises involving small amounts of muscle mass is a reduced release of $\mathrm{H}+$ ions into the extracellular environment (Soller et al., 2007). Therefore, although research has shown that isometric handgrip exercise can lead to a pronounced decrease in intramuscular $\mathrm{pH}$ (Nielsen et al., 2002; Soller et al., 2007), intracellular $\mathrm{pH}$ regulation could not possibly be compromised by a lower efficiency of the intramuscular $\mathrm{pH}$ extracellular mechanisms regulating acid-base balance.

In addition, the isometric contraction adopted may also have been responsible for the lack of positive response to $\mathrm{NaHCO}_{3}$ supplementation, due to the decrease in oxygen saturation and likely protagonism of poor availability of muscle oxygen, leading to the acceleration of fatigue (Akima and Ando, 2016). Lopes-Silva et al. (2018), when evaluating performance of taekwondo athletes in a dynamic work test (simulated combat), showed that $\mathrm{NaHCO}_{3}$, besides increasing glycolytic contribution, significantly improved athletes' performance in the test. Perhaps this result was due to generalized fatigue, resulting from the dynamic characteristic of combat and having a greater effect on blood $\mathrm{pH}$.

From our results, it can be concluded that $\mathrm{NaHCO}_{3}$ - supplementation does not generate adverse responses resulting in gastrointestinal discomfort, but promotes a metabolic alkalosis state, which has been shown not to benefit performance, evaluated in the intermittent isometric contraction test of the flexor muscles of the lower limbs, i.e., fingers held to fatigue. However, further studies are needed to better elucidate the possible ergogenic effect of $\mathrm{NaHCO}_{3}-$ supplementation for combat sports, of which performance is determined by the ability to perform isometric contractions.

\section{Acknowledgements}

We acknowledge support from Coordenação de Aperfeiçoamento de Pessoal de Nível Superior (CAPES), and Federal University of Juiz de Fora, Brazil, who granted his University Hospital the collection of blood variables. 


\section{References}

Akima H, Ando R. Oxygenation and neuromuscular activation of the quadriceps femoris including the vastus intermedius during a fatiguing contraction. Clin Physiol Funct Imaging, 2017; 37: 750-758

Artioli GG, Gualano B, Coelho DF, Benatti FB, Gailey AW, Lancha AH. Does sodium-bicarbonate ingestion improve simulated judo performance? Int J Sport Nutr Exerc Metab, 2007; 17: 206-217.

Beck TW. The importance of a priori sample size estimation in strength and conditioning research. J Strength Cond Res, 2013; 27: 2323-2337

Bishop D, Claudius B. Effects of induced metabolic alkalosis on prolonged intermittent-sprint performance. Med Sci Sports Exerc, 2005; 37: 759-767

Cameron SL, McLay-Cooke RT, Brown RC, Gray AR, Fairbairn KA. Increased blood pH but not performance with sodium bicarbonate supplementation in elite rugby union players. Int J Sport Nutr Exerc Metab, 2010; 20: 307-321

Carr AJ, Slater GJ, Gore CJ, Dawson B, Burke LM. Effect of sodium bicarbonate on [HCO3-], pH, and gastrointestinal symptoms. Int J Sport Nutr Exerc Metab, 2011; 21: 189-194

Chin ER, Allen DG. The contribution of $\mathrm{pH}$-dependent mechanisms to fatigue at different intensities in mammalian single muscle fibers. J Physiol, 1998; 512: 831-840

Chycki J, Golas A, Halz M, Maszczyk A, Toborek M, Zajac A. Chronic Ingestion of Sodium and Potassium Bicarbonate, with Potassium, Magnesium and Calcium Citrate Improves Anaerobic Performance in Elite Soccer Players. Nutrients, 2018a; 10: 1-12

Chycki J, Kurylas A, Maszczyk A, Golas A, Zajac A. Alkaline water improves exercise-induced metabolic acidosis and enhances anaerobic exercise performance in combat sport athletes. Plos One, 2018b; 13: e0205708

Driller MW, Gregory JR, Williams AD, Fell JW. The effects of chronic sodium bicarbonate ingestion and interval training in highly trained rowers. Int J Sport Nutr Exerc Metab, 2013; 23: 40-47

Durkalec-Michalski K, Zawieja EE, Podgórski T, Łoniewski I, Zawieja BE, Warzybok M, Jeszka J. The effect of chronic progressive-dose sodium bicarbonate ingestion on CrossFit-like performance: A doubleblind, randomized cross-over trial. PloS One, 2018; 13: e0197480

Dworkin RH, Turk DC, Farrar JT, Haythornthwaite JA, Jensen MP, Katz NP, Kerns RD, Stucki G, Allen RR, Bellamy N, Carr DB, Chandler J, Cowan P, Dionne R, Galer BS, Hertz S, Jadad AR, Kramer LD, Manning DC, Martin S, McCormick CG, McDermott MP, McGrath P, Quessy S, Rappaport BA, Robbins W, Robinson JP, Rothman M, Royal MA, Simon L, Stauffer JW, Stein W, Tollett J, Wernicke J, Witter J. Core outcome measures for chronic pain clinical trials: IMMPACT recommendations. Pain, 2005; 113: 9-19

Fabiato A, Fabiato F. Effects of $\mathrm{pH}$ on the myofilaments and the sarcoplasmic reticulum of skinned cells from cardiac and skeletal muscles. J Physiol, 1978; 276: 233-255

Faul F, Erdfelder E, Lang AG, Buchner A. G* Power 3: A flexible statistical power analysis program for the social, behavioral, and biomedical sciences. Behav Res Methods, 2007; 39: 175-191

Ferreira LHB, Smolarek AC, Chilibeck PD, Barros MP, McAnulty SR, Schoenfeld BJ, Zandona BA, SouzaJunior TP. High doses of sodium bicarbonate increase lactate levels and delay exhaustion in a cycling performance test. Nutrition, 2019; 60: 94-99

Franchini E, Del Vecchio FB, Matsushigue KA, Artioli GG. Physiological profiles of elite judo athletes. Sports Med, 2011; 41: 147-166

Hunter SK, Griffith EE, Schlachter KM, Kufahl TD. Sex differences in time to task failure and blood flow for an intermittent isometric fatiguing contraction. Muscle Nerve, 2009; 39: 42-53

Jeukendrup AE, Vet-Joop K, Sturk A, Stegen JH, Senden J, Saris WH, Wagenmakers AJ. Relationship between gastro-intestinal complaints and endotoxemia, cytokine release and the acute-phase reaction during and after a long-distance triathlon in highly trained men. Clin Sci, 2000; 98: 47-55

Junior AHL, de Salles Painelli V, Saunders B, Artioli GG. Nutritional strategies to modulate intracellular and extracellular buffering capacity during high-intensity exercise. Sports Med, 2015; 45: 71-81

Kumstát M, Hlinský T, Struhár I, Thomas A. Does Sodium Citrate Cause the Same Ergogenic Effect as Sodium Bicarbonate on Swimming Performance? J Hum Kinet, 2018; 65: 89-98 
Lopes-Silva JP, Da Silva Santos JF, Artioli GG, Loturco I, Abbiss C, Franchini E. Sodium bicarbonate ingestion increases glycolytic contribution and improves performance during simulated taekwondo combat. Eur J Sport Sci, 2018; 18: 431-440

McNaughton LR. Bicarbonate ingestion: effects of dosage on 60 s cycle ergometry. J Sports Sci, 1992; 10: 415423

Nielsen HB, Hein L, Svendsen LB, Secher NH, Quistorff B. Bicarbonate attenuates intracellular acidosis. Acta Anaesthesiol Scand, 2002; 46: 579-584

Oliveira M, Moreira D, Godoy JRP, Nascimento CA. Evaluation of the palmar grip strength in jiu-jitsu athletes in competitive level. $R$ Bras Ci e Mov, 2006; 14: 63-70

Requena B, Zabala M, Padial P, Feriche B. Sodium bicarbonate and sodium citrate: ergogenic aids? J Strength Cond Res, 2005; 19: 213-224

Siegler JC, Mudie K, Marshall P. The influence of sodium bicarbonate on maximal force and rates of force development in the triceps surae and brachii during fatiguing exercise. Exp Physiol, 2016; 101: 13831391

Siegler JC, Marshall P. The effect of metabolic alkalosis on central and peripheral mechanisms associated with exercise-induced muscle fatigue in humans. Exp Physiol, 2016; 100: 519-530

Siegler JC, Marshall P, Pouslen MK, Nielsen NPB, Kennedy D, Green S. The effect of $\mathrm{pH}$ on fatigue during submaximal isometric contractions of the human calf muscle. Eur J Appl Physiol, 2015; 115: 565-577

Siegler JC, Midgley AW, Polman RC, Lever R. Effects of various sodium bicarbonate loading protocols on the time-dependent extracellular buffering profile. J Strength Cond Res, 2010; 24: 2551-2557

Siegler JC, Hirscher K. Sodium bicarbonate ingestion and boxing performance. J Strength Cond Res, 2010; 24: 103-108

Soller BR, Hagan RD, Shear M, Walz JM, Landry M, Anunciacion D, Orquiola A, Heard SO. Comparison of intramuscular and venous blood $\mathrm{pH}, \mathrm{PCO}(2)$ and $\mathrm{PO}(2)$ during rhythmic handgrip exercise. Physiol Meas, 2007; 28: 639-649

Spriet LL, Lindinger MI, McKelvie RS, Heigenhauser GJ, Jones NL. Muscle glycogenolysis and H+ concentration during maximal intermittent cycling. J Appl Physiol, 1989; 66: 8-13

Van Montfoort MC, Van Dieren L, Hopkins WG, Shearman JP. Effects of ingestion of bicarbonate, citrate, lactate, and chloride on sprint running. Med Sci Sports Exerc, 2004; 36: 1239-1243

Verbitsky O, Mizrahi J, Levin M, Isakov E. Effect of ingested sodium bicarbonate on muscle force, fatigue, and recovery. J Appl Physiol, 1997; 83: 333-337

Westerblad H, Allen DG. The influence of intracellular $\mathrm{pH}$ on contraction, relaxation and [Ca2+] i in intact single fibers from mouse muscle. J Physiol, 1993; 466: 611-628

\section{Corresponding author:}

\section{Marcelo Ricardo Cabral dias}

Laboratory of Exercise Physiology and Morphofunctional Assessment,

Granbery Methodist College, Juiz de Fora, Brazil.

Rua Floriano Peixoto, 937/503, Centro, Juiz de Fora, MG

Phone: +55 32 99194-0154

E-mail: diasmr@gmail.com 